\title{
Physical inactivity in COPD and increased patient perception of dyspnea
}

This article was published in the following Dove Press journal:

International Journal of COPD

26 October 2012

Number of times this article has been viewed

\section{Milla Katajisto' \\ Henna Kupiainen' \\ Piritta Rantanen' \\ Ari Lindqvist' \\ Maritta Kilpeläinen ${ }^{2}$ \\ Heikki Tikkanen ${ }^{3}$ \\ Tarja Laitinen ${ }^{2}$}

'Clinical Research Unit for Pulmonary Diseases and Division of Pulmonology, Helsinki University Central Hospital, Helsinki, Finland; ${ }^{2}$ Department of Pulmonary Diseases and Clinical Allergology, Turku University Hospital and University of Turku, Turku, Finland; ${ }^{3}$ Department of Sports and Exercise Medicine, Institute of Clinical Medicine, Helsinki University and Foundation of Sports and Exercise Medicine, Helsinki, Finland
Correspondence: Milla Katajisto Mechelininkatu 39 a 7, 00250 Helsinki, Finland

Email milla.katajisto@hus.fi
Objective: To study patients' levels of exercise activity and the clinical characteristics that relate to physical activity and inactivity among patients with chronic obstructive pulmonary disease (COPD).

Methods: A postal questionnaire was administered to 719 patients with COPD in 2010; patients were recruited from the Helsinki and Turku University Central Hospitals in Finland and have been followed since 2005. The questionnaire asked participants about their exercise routines and other daily activities, potential restrictions to exercise, health-related quality of life, and subjective sensations of dyspnea upon exertion.

Results: A total of $50 \%$ of the participants reported exercising $>2$ times a week throughout the year. The proportion of the exercise inactive patients increased in parallel with disease progression, but the participants exhibited great variation in the degree of activity as well as in sport choices. Year-round activity was better maintained among patients who exercised both indoors and outdoors. Training activity was significantly correlated with patients' reported subjective dyspnea $(r=0.32, P<0.001)$, health-related quality of life $(r=0.25, P<0.001)$, mobility score $(r=0.37, P<0.001)$, and bronchial obstruction $(r=0.18, P<0.001)$. Active patients did not differ from inactive patients in terms of sex, age, smoking status, somatic comorbidities, or body mass index. Irrespective of the level of severity of patients' COPD, the most significant barrier to exercising was the subjective sensation of dyspnea.

Conclusion: When a patient with COPD suffers from dyspnea and does not have regular exercise routines, the patient will most likely benefit from an exercise program tailored to his or her physical capabilities.

Keywords: COPD, physical fitness, exercise training, physical activity, pulmonary rehabilitation

\section{Introduction}

Patients with chronic obstructive pulmonary disease (COPD) are reported to be less physically active than both their age- and sex-matched healthy counterparts and patients with other chronic diseases such as rheumatoid arthritis or diabetes. ${ }^{1-5}$ On the other hand, COPD patients who do remain physically active have lower mortality rates, better performance status, and better health-related quality of life (HRQoL) ${ }^{6-10}$ It is poorly understood why a significant proportion of patients with very severe bronchial obstruction can maintain remarkable levels of physical activity, while others start to lose their exercise capacity at early stages of the disease. ${ }^{6-12}$ Medical literature on clinical variables associated with physically inactive COPD patients, and data about their willingness to participate in pulmonary rehabilitation programs is sparse. The types of exercise activities that COPD patients favor are also largely unknown. 
COPD is the only disease associated with consistently rising hospital admission and mortality rates worldwide, ${ }^{13,14}$ which results in significant health care costs. Physical inactivity is recognized as a significant risk factor for the exacerbation of COPD, which, in turn, can accelerate the decline of lung function..$^{7-9,15}$ Pulmonary rehabilitation is shown to be especially effective in preventing the exacerbation of the disease. ${ }^{16-18}$ There is also cumulative evidence that regular exercise improves patients' exercise capacity, symptom tolerance, and HRQoL. Evidence pertaining to the positive effects of pulmonary rehabilitation programs on patient's HRQoL are less abundant. ${ }^{19-23}$

While the short-term benefits of pulmonary rehabilitation programs are extremely encouraging, more research is needed to assess the long-term results of pulmonary rehabilitation. Previous studies suggest that the positive effects of pulmonary rehabilitation on a patient's exercise capacity might be lost within a year. ${ }^{19,20}$ In order to develop more successful pulmonary rehabilitation programs, our aim in the present study was to improve the understanding of COPD patients' spontaneous exercise routines, the sports they practice, the potential barriers of exercising, and the role of dyspnea in a patient's capacity to exercise. Since the cohort that was examined in this study also displayed very severe stages of the disease, the overall physical activity among COPD patients was further studied by quantifying their daily activities and overall mobility. Our expectation was that COPD patients exercise less than is recommended according to health-promotion strategies, and that the sports in which they are able to participate are limited. We suspected that severe bronchial obstruction, comorbidities, impaired diffusion capacity, and old age would be the risk factors associated with physical inactivity. We also inquired as to whether the study subjects had previously participated in a pulmonary rehabilitation program or received guidance on physical training, and about their interest in participating in a pulmonary rehabilitation program. These COPD patients are well-defined and have been followed since 2005, which allowed us to add several clinical background variables to the analysis.

\section{Materials and methods Study population}

All of the study subjects were identified from the Finnish chronic airway disease cohort. ${ }^{24}$ The cohort was recruited from the pulmonary clinics of the Helsinki and Turku University Central Hospitals, Finland, from 2005-2007, and their medical records were retrospectively evaluated starting from the onset of each patient's disease. Smoking-related COPD or chronic bronchitis was verified for 959 patients. All participants provided their informed consent and the researchers were able to collect and analyze the patients' medical records; furthermore, patients also agreed to participate in follow-up studies over the proceeding 10 years. A total of 19 participants withdrew from the study. The annual death rate noted in the cohort was $3.6 \%$. The study was approved by the Ethics Committee of the Hospital District of Helsinki and Uusimaa.

\section{Assessment of physical activity}

All surviving and still actively participating COPD patients ( $\mathrm{n}=827)$ were mailed a questionnaire asking questions about their exercise activities, time spent on daily life activities, and fitness training between March and April 2010 (a translated version of the questionnaire is available in the Supplementary material [Table S1]). Following one reminder, the overall response rate was $87 \%(n=719)$. Exercise activity during winter and the rest of the year were inquired about separately (Q1B and Q1A, respectively) by the question: "How often do you exercise at least half an hour at a time with the intensity which makes you at least mildly short of breath and perspire?" Questions Q2 and Q3 were directed to those patients who were still working. Daily life activities and the amount of time spent on household chores and other leisure activities were inquired by question Q4. The questions Q1-Q4 were previously used in the Finnish Health and Functional Capacity Study. ${ }^{25}$ Question Q6 was modified from the version used in a previous study assessing the barriers of physical activity among elderly adults. ${ }^{26}$ The British Medical Research Council (MRC) dyspnea scale was used to evaluate patients' subjective dyspnea (Q8). ${ }^{27}$ Response rates for individual questions varied between $96 \%$ and $100 \%$ (Table S1).

\section{Terms defining patient's physical activity}

Based on the recommendations of the American College of Sports Medicine and the American Heart Association, ${ }^{28}$ patients were categorized as being "physically active" when they reported exercising at least 2-3 times a week and for at least 30 minutes each time, with an intensity causing shortness of breath and perspiration, throughout the year.

The exercise time per week was estimated based on Q1A and Q1B as follows: (1) daily $=210$ minutes/week; (2) 2-3 times a week $=75$ minutes/week; (3) once a week $=30$ minutes/ week; (4) 2-3 times a month = 19 minutes/week; (5) a couple of times a year or less $=0$ minutes $/$ week. 
"Daily life activity" was estimated by summing up the amount of time during which patients performed different domestic/household chores and engaged in leisure activities (minutes/week; Q4). Question Q7 was designed to capture the most profound stages of physical inactivity. The "mobility score" was classified based on either no or minor restrictions in normal life (when the patient is mostly up all day and does light household chores in and outside of the home as needed), or based on the most severe restrictions (the patient rests all day and cannot leave his or her house without help).

\section{Assessment of clinical characteristics}

The participants' HRQoL was assessed using the selfcompleted, airway-specific AQ20 $29-32$ and generic $15 \mathrm{D}^{33}$ instruments. Each of the hospitals, health care centers, and other outpatient clinics that treated the patients was contacted to gather a complete medical history for each participant. The medical history encompassed the period at least 5 years prior to recruitment. The patients' social security numbers were used to combine the data from different sources and to link the data to each patient. From the medical records, we identified the results of the latest flow-volume spirometry including bronchodilation tests, and we also acquired information about each patient's weight, height, and smoking status. The latest spirometry was taken on average $1.7 \pm 1.9$ (SD) years before recruitment. The diffusing capacity test was only available for a subgroup of patients $(\mathrm{n}=294)$.

The reference values for forced expiratory volume in 1 second $\left(\mathrm{FEV}_{1}\right)$ and volume- and blood hemoglobin levelcorrected diffusing capacity (DLCOcVA) were validated across large Finnish population samples. ${ }^{34}$ All of the diagnoses stated in the medical records were carefully evaluated, and particular attention was paid to the time of disease onset and certainty of the diagnosis. The category "coronary disease" included patients who had a myocardial infarct, acute coronary syndrome, or angina pectoris diagnosed by an internist. "Cardiovascular diseases" consisted of patients having one of the following diseases: coronary artery disease, cerebrovascular disease, or peripheral artery occlusive disease. Chronic alcoholism, alcohol use disorder, and treatment of an alcohol use-related disorder were all categorized as "alcohol abuse." A wide range of psychotic disorders - including long-lasting clinical depression and anxiety disorders that required regular medication - were categorized as "psychiatric condition." "Diabetes" included both type 1 and type 2 diabetes patients being treated with medication.

\section{Statistical analysis}

All statistical analyses were performed with the SPSS statistical software packages (version 17.0; IBM Corporation, Armonk, NY). Comparisons between the mean differences of the demographic and clinical characteristics of the patients in the subgroups were conducted using either the Chi-squared test or the Mann-Whiney test. Correlations between ordinal variables were compared using the Spearman's correlation coefficient $(r)$. The logistic regression analysis was used to determine the independent risk factors associated with physical inactivity. The potential interactions between $\mathrm{FEV}_{1}$ groups and exercise time, exercise activity, daily activity, and mobility were tested with two-way analysis of variance.

\section{Results \\ Study subjects}

The study cohort represented patients with smoking-related chronic bronchitis or COPD across all stages of the disease. The cohort was followed by way of their medical records since the year 2000. During March and April 2010, all participants received a postal questionnaire inquiring about their present exercise routines, sports that they practice, exercise restrictions, other daily activities, their mobility score, and their subjective level of dyspnea. During that time, the mean age in the cohort was 63 years and $40 \%$ of the patients were women. A total of $12 \%$ of the patients were employed and $52(7.4 \%)$ of them indicated they had a physically strenuous job. The clinical characteristics collected from the medical records are shown in Table 1, and the translation of the questionnaire and the patients' responses are shown in Table S1.

\section{Physical activity among COPD patients}

When patients were divided into active and inactive categories based on their exercise routines, common demographic and clinical determinants such as age, sex, comorbidities, or health behavior (continuation of smoking and body mass index [BMI]) showed very little differences between the groups. $\mathrm{FEV}_{1}$, forced vital capacity (FVC), and diffusion capacity were significantly better in physically active patients (Table 1). Exercise activity decreased in parallel with the progression of the disease $(P<0.001)$ (Figure 1). The proportion of patients with $\mathrm{FEV}_{1}>80 \%$ of the expected value who exercised $>2$ times a week throughout the year was $60 \%(\mathrm{n}=60)$; with $\mathrm{FEV}_{1}$ 65\%-80\% of expected was $51 \%(\mathrm{n}=96)$; with $\mathrm{FEV}_{1} 40 \%-64 \%$ of expected was $50 \%(\mathrm{n}=143)$; and with $\mathrm{FEV}_{1}<40 \%$ of expected was $33 \%(\mathrm{n}=35)(P=0.001)$.

Exercise activity was lower during the winter than during the rest of the year across all levels of severity of 
Table I Comparison of the clinical characteristics between physically active (exercise $>2-3$ times a week) and inactive COPD patients

\begin{tabular}{|c|c|c|c|}
\hline $\begin{array}{l}\text { Clinical } \\
\text { characteristics }\end{array}$ & All patients & $\begin{array}{l}\text { Physically } \\
\text { active }\end{array}$ & $\begin{array}{l}\text { Physically } \\
\text { inactive }\end{array}$ \\
\hline \multicolumn{4}{|l|}{ Sex } \\
\hline Male & $419(60 \%)$ & $210(61 \%)$ & $209(59 \%)$ \\
\hline Female & $280(40 \%)$ & 133 (39\%) & I 47 (4I\%) \\
\hline Age mean (SD) & $63.4(7.0)$ & $63.3(7.0)$ & $63.3(6.9)$ \\
\hline BMI mean (SD) & $26.6(5.2)$ & $26.5(4.8)$ & $26.7(5.6)$ \\
\hline \multicolumn{4}{|l|}{$\begin{array}{l}\text { Change in weight within } \\
\text { the last year }(q \mid 6)\end{array}$} \\
\hline No change & $364(53 \%)$ & $193(58 \%)$ & $|7|(48 \%)^{*}$ \\
\hline Increase $>2 \mathrm{~kg}$ & $190(28 \%)$ & $81(24 \%)$ & $109(31 \%)$ \\
\hline Decrease $>2 \mathrm{~kg}$ & $134(20 \%)$ & 61 (18\%) & $73(21 \%)$ \\
\hline \multicolumn{4}{|l|}{ Smoking (Q I5) } \\
\hline Current regular & $210(30 \%)$ & $90(27 \%)$ & $120(34 \%)^{*}$ \\
\hline Current irregular & $59(9 \%)$ & $25(7 \%)$ & $34(10 \%)$ \\
\hline Ex-smoker & $422(6 I \%)$ & $222(66 \%)$ & $200(57 \%)$ \\
\hline \multicolumn{4}{|c|}{ Spirometry mean (SD) } \\
\hline $\mathrm{FEV}, \%$ of expected & $60.1(18.5)$ & $63.1(18.0)$ & $57.6(18.7)^{* *}$ \\
\hline FVC $\%$ of expected & $75.2(17.7)$ & $77.8(17.5)$ & $72.9(17.7)^{* *}$ \\
\hline $\mathrm{FEV}_{1} / \mathrm{FVC} \%$ & $64.5(13.7)$ & $65.6(12.3)$ & $63.7(14.5)$ \\
\hline \multicolumn{4}{|l|}{ Diffusion capacity§ } \\
\hline DLCOcVA $\%$ of expected & $78.5(22.3)$ & $81.7(21.4)$ & $74.7(22.6)^{* *}$ \\
\hline \multicolumn{4}{|l|}{ Coexisting diseases } \\
\hline Hypertension & $295(42 \%)$ & $|4|$ (4I\%) & I 54 (43\%) \\
\hline Psychiatric conditions $* * *$ & 147 (2।\%) & 64 (19\%) & $83(23 \%)$ \\
\hline Coronary disease & $132(19 \%)$ & $58(17 \%)$ & $74(21 \%)$ \\
\hline Alcohol abuse & $102(15 \%)$ & 44 (13\%) & $58(17 \%)$ \\
\hline Diabetes & $99(14 \%)$ & 43 (13\%) & $56(16 \%)$ \\
\hline Cerebrovascular disease & $49(7 \%)$ & $23(7 \%)$ & $26(7 \%)$ \\
\hline Peripheral vascular disease & $38(6 \%)$ & $24(7 \%)$ & $14(4 \%)$ \\
\hline
\end{tabular}

Notes: $* P<0.05$ for the Chi-square $2 \times 3$ contingency table; $* * P<0.01$ when active and inactive groups were compared; ${ }^{* * *}$ medication in use; ${ }^{\S}$ data available for 294 patients.

Abbreviations: COPD, chronic obstructive pulmonary disease; BMI, body mass index; $\mathrm{FEV}_{1}$, forced expiratory volume in I second; FVC, forced vital capacity; DLCOcVA, diffusing capacity corrected for alveolar volume.

the disease (Figure 1). Eighty-seven patients (20\%) who exercised actively in the summer became inactive during the winter. Year-round exercise activity correlated significantly with the level of bronchial obstruction $(r=-0.14, P<0.01)$, diffusing capacity $(r=-0.20, P<0.01)$, mobility score $(\mathrm{Q} 7)$ $(r=-0.31, P<0.01)$, daily life activity (Q4) $(r=-0.14$, $P<0.01)$, generic $(r=-0.23, P<0.01)$ and airway-specific HRQoL $(r=0.19, P<0.01)$ (Table S2). Overall, the observed correlations were statistically significant, but many of these relationships were rather weak.

\section{Interest in pulmonary rehabilitation}

A total of 233 patients had previously been given guidance for training by health care professionals, and $15 \%(\mathrm{n}=96)$ had taken part in a 2-week inpatient $(\mathrm{n}=71)$ or outpatient $(\mathrm{n}=25)$ rehabilitation program (Table 2$)$. A total of $14 \%$

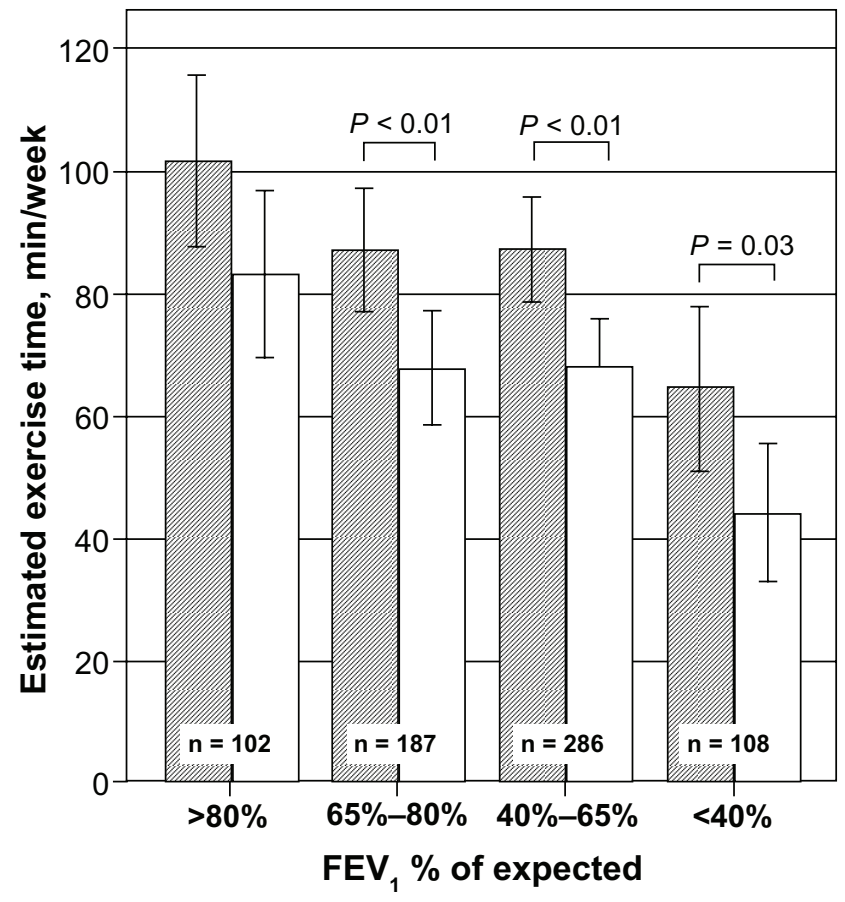

Figure I Seasonal changes in estimated exercise time (minutes/week) of patients with different $\mathrm{FEV}$, \% values.

Notes: Dark bars represent spring, summer, and autumn; light bars represent winter. Significant $P$-values of the difference between winter and other seasons within the $\mathrm{FEV}$, \% groups are given above the bars.

Abbreviation: $\mathrm{FEV}_{1}$, forced expiratory volume in I second.

$(n=94)$ of all patients had received exercise guidance from physicians; 58 of these patients (18\%) were active and $36(11 \%)$ were inactive. A history of competing in sports as a youth was not associated with the maintenance of exercise activity among the COPD patients. Sixty-two percent of the inactive patients compared with $54 \%$ of the active patients showed an interest in pulmonary rehabilitation $(P<0.01)$. Those who were interested were slightly younger (62.9 versus 64.1 years) than those who were not, but no difference was found based on disease severity, sex, or coexisting disease profiles. Whilst $71 \%$ of patients reported that COPD significantly restricts their exercising (Q9), the mobility score (Q7) was significantly pronounced within each $\mathrm{FEV}_{1}$ class among inactive patients when compared to active patients (Figure 2). In daily life activities (Q4) the same trend was observed, even though the difference between active and inactive patients was significant only at the later stages of the disease, particularly when $\mathrm{FEV}_{1} \leq 64 \%$ of expected was noted.

\section{Dyspnea}

Subjective dyspnea, assessed by the MRC dyspnea scale, showed constantly stronger correlations with patients' exercise activity $(r=0.27, P<0.01)$, daily life activity 
Table 2 Comparison of the patient-reported outcomes between physically active and inactive (exercise $\geq 2-3$ times a week) COPD patients

\begin{tabular}{|c|c|c|c|}
\hline Patient-reported outcomes & All patients & $\begin{array}{l}\text { Physically } \\
\text { active }\end{array}$ & $\begin{array}{l}\text { Physically } \\
\text { inactive }\end{array}$ \\
\hline \multicolumn{4}{|l|}{ Employed at the time of the survey (Q3) } \\
\hline Yes & $88(12 \%)$ & $38(11 \%)$ & $50(14 \%)$ \\
\hline No & $598(88 \%)$ & $299(89 \%)$ & 299 (86\%) \\
\hline \multicolumn{4}{|l|}{ Competed in sports in youth (QI0) } \\
\hline Yes & $236(35 \%)$ & 118 (35\%) & $118(34 \%)$ \\
\hline No & $446(65 \%)$ & $216(65 \%)$ & $230(66 \%)$ \\
\hline More than one way of exercising (Q5) & $321(47 \%)$ & $204(62 \%)$ & $117(34 \%) * *$ \\
\hline Everyday activities (Q4) & $312(284 \%)$ & $347(288 \%)$ & $284(276 \%)^{* * *}$ \\
\hline \multicolumn{4}{|l|}{ minutes/week mean (SD) } \\
\hline \multicolumn{4}{|c|}{ Guidance for exercising because of COPD (QII) } \\
\hline Yes & $233(36 \%)$ & $113(36 \%)$ & $120(36 \%)$ \\
\hline Yes by physician & 94 (I4\%) & $58(18 \%)$ & $36(11 \%)^{* *}$ \\
\hline Yes by nurse & $56(9 \%)$ & $31(10 \%)$ & $25(7 \%)$ \\
\hline Yes by physiotherapist & $135(2 \mid \%)$ & $59(19 \%)$ & $76(23 \%)$ \\
\hline \multicolumn{4}{|c|}{ Rehabilitation due to pulmonary disease $(\mathrm{Q} \mid 2)$} \\
\hline Yes & $96(15 \%)$ & $46(14 \%)$ & $50(15 \%)$ \\
\hline No & $560(85 \%)$ & $275(86 \%)$ & $285(85 \%)$ \\
\hline \multicolumn{4}{|l|}{ Interest in rehabilitation (Q।4) } \\
\hline Yes & $374(58 \%)$ & 168 (54\%) & $206(62 \%)^{*}$ \\
\hline No & $273(42 \%)$ & $146(46 \%)$ & 127 (38\%) \\
\hline \multicolumn{4}{|l|}{ Health-related quality of life } \\
\hline Respiratory specific mean (SD) & $8.1(4.9)$ & $7.2(4.8)$ & $9.0(4.9)^{* *}$ \\
\hline Generic mean (SD) & $0.80(0.10)$ & $0.83(0.09)$ & $0.78(0.1 \mathrm{I})^{* *}$ \\
\hline \multicolumn{4}{|c|}{ Enough information about the role of physical } \\
\hline \multicolumn{4}{|l|}{ activity in the prognosis of COPD (QI3) } \\
\hline Yes & $303(46 \%)$ & $|5|(47 \%)$ & $152(45 \%)$ \\
\hline No & $357(54 \%)$ & $168(53 \%)$ & $189(55 \%)$ \\
\hline \multicolumn{4}{|l|}{ MRC dyspnea scale (Q8) } \\
\hline 0 & $64(10 \%)$ & $42(13 \%)$ & $22(7 \%)^{* * *}$ \\
\hline 1 & $253(39 \%)$ & 144 (46\%) & $109(33 \%)$ \\
\hline 2 & $196(31 \%)$ & 102 (33\%) & 94 (29\%) \\
\hline 3 & 93 (I5\%) & $20(6 \%)$ & 77 (22\%) \\
\hline 4 & $35(6 \%)$ & $5(2 \%)$ & 31 (9\%) \\
\hline
\end{tabular}

Notes: $* P<0.05 ; * * P<0.01$ when active and inactive groups were compared; $* * * P<0.01$ for the Chi-square $2 \times 5$ contingency table.

Abbreviations: COPD, chronic obstructive pulmonary disease; MRC, British Medical Research Council.

$(r=-0.37, P<0.01)$, mobility $(r=-0.46, P<0.01)$, airwayrelated $(r=0.33, P=0.01)$, and generic HRQoL $(r=-0.40$, $P<0.01)$ levels than the $\mathrm{FEV}_{1}$ or the diffusing capacity corrected for alveolar volume (Table S2). When $\mathrm{FEV}_{1}$ was less than $65 \%$ of expected, the subjective perception of dyspnea was significantly stronger among inactive than active patients (Figure 3). Using two-way analysis of variance, we found a significant interaction $(P=0.016)$ between the $\mathrm{FEV}_{1}$ and activity groups, suggesting that the sensation of dyspnea becomes disproportionally stronger as lung function decreases among the inactive patients when compared to the decrease in lung function among the active patients. The explanatory variables in Figures 1 and 2 were also tested, but no significant interactions between the variables and physical activity were found.

\section{Barriers to exercising}

The most frequently reported reasons preventing patients from exercising (Q6) were sensation of dyspnea (66\%), pain $(36 \%)$, other illnesses (42\%), discomfort of strenuous exercise (20\%), and poor weather (17\%) (Table S1). The most common exercise-limiting diseases reported were musculoskeletal disorders $(\mathrm{n}=92)$ and ischemic heart conditions $(n=41)$.

\section{Physically active patients}

When the active patients were studied in greater detail, their common factor seemed to be the greater variety of sport activities in which they engaged. When walking was excluded, the active patients $(n=343)$ practiced a specific sport more frequently than inactive patients (215 patients, 

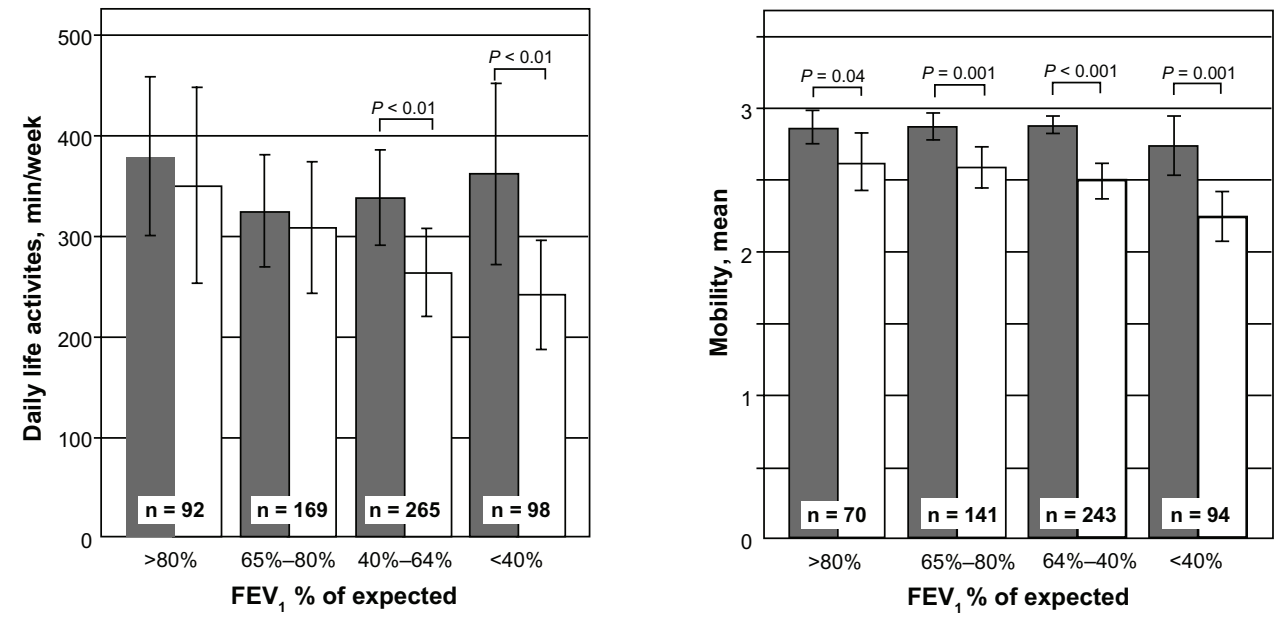

Figure 2 Daily life activities (minutes/week) and mobility score in different FEV, \% classes.

Notes: Dark bars represent active patients; light bars represent inactive patients; Mobility score I = rests inside most of the day, and cannot get out without help; 2 = stays up inside most of the day; 3 = moves in and out, doing light household chores when needed.

Abbreviation: $\mathrm{FEV}_{1}$, forced expiratory volume in I second.

or $63 \%$, versus 119 patients, or $33 \% ; P<0.001$ ). The top 12 sports that COPD patients favored differed greatly in terms of their metabolic equivalents, which are used to compare the intensity between different types of sport activities (Table 3). ${ }^{35}$ Metabolic equivalent values ranged from 2.0 (slow walking) to 6.0 (swimming and skiing). In addition, COPD patients adopted a wide range of sport activities, including skiing, golf, yoga, asahi (Chinese-style gymnastics), badminton,

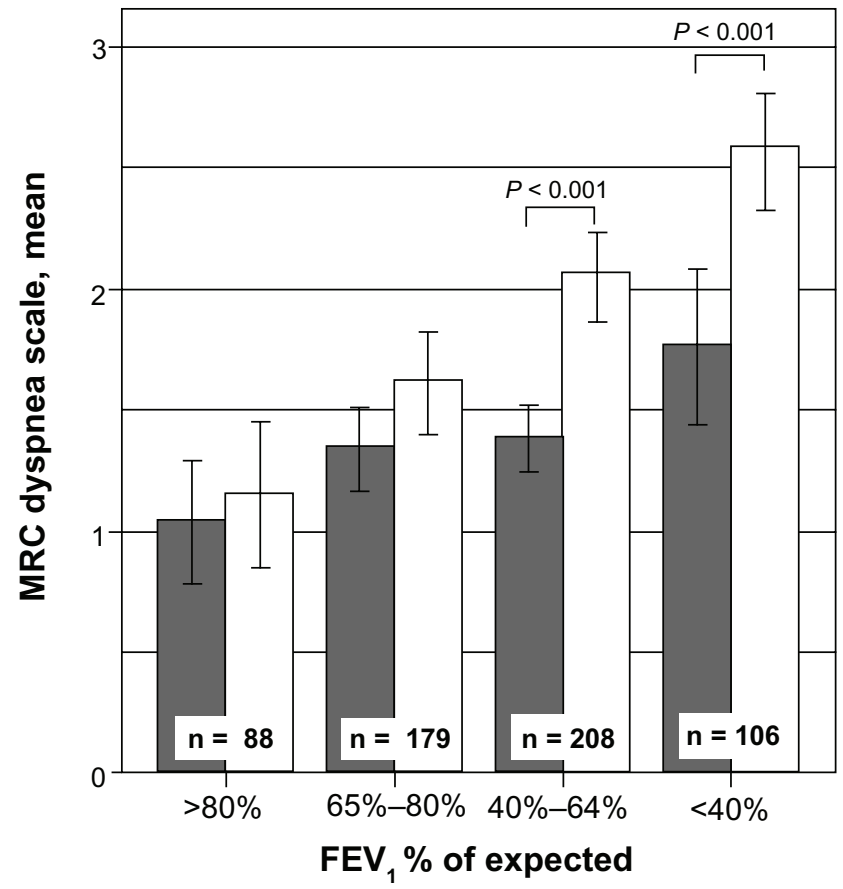

Figure 3 MRC dyspnea scale in different FEV, \% classes among active and inactive patients as represented in the dark and light bars, respectively.

Abbreviations: MRC, British Medical Research Council; FEV ${ }_{1}$, forced expiratory volume in I second. bowling, rowing, downhill skiing, sailing, and hiking. Even though high-intensity activities were practiced less often among patients with severe bronchial obstruction, some patients could still continue swimming, skiing, and participating in ballgames (Table 3 ). A total of 35 patients $(32 \%)$ with $\mathrm{FEV}_{1}<40 \%$ of predicted levels continued to exercise actively.

\section{Clinical variables explaining variability in physical activity levels}

In the multivariate model, we found that subjective dyspnea remained by far the most significant marker (OR 7-12, CI 95\% 3-38, $P>0.001$ at dyspnea levels 3-4) for exercise inactivity when the model was adjusted for sex, age, smoking status, BMI, and common comorbidities such as cardiovascular diseases, diabetes, psychiatric conditions, and alcohol diseases. $\mathrm{FEV}_{1}$ explained exercise inactivity only at the late state of the disease (OR 3.5, CI 95\% 1.8-6.9, when $\mathrm{FEV}_{1}<40 \%$ of expected was observed).

\section{Discussion}

\section{Main findings}

Based on the present study, when COPD patients' exercise activity was assessed by a self-reported questionnaire, 51\% of the study subjects did not achieve the recommended minimum physical activity levels required to promote and maintain their health, as provided by the American College of Sports Medicine and the American Heart Association. ${ }^{28}$ Most interestingly, we found that patients' perceptions of dyspnea correlated more strongly with their exercise activity, 
Table 3 Most popular sports practiced by the COPD patients according to airway obstruction

\begin{tabular}{|c|c|c|c|c|c|c|}
\hline Sports & MET $^{a}$ & FEV $_{1}>\mathbf{8 0} \%$ & FEV , 65\%-80\% & FEV, $40 \%-64 \%$ & FEV $_{1}<\mathbf{4 0} \%$ & Total \\
\hline Walking & 3.8 & 51 & 73 & 81 & 11 & 216 \\
\hline Cycling & 4.0 & 11 & 22 & 33 & 2 & 68 \\
\hline Swimming & 6.0 & 13 & 17 & 16 & 2 & 48 \\
\hline Gym & 4.5 & 10 & 17 & 14 & 6 & 47 \\
\hline Water-running & 6.0 & 4 & 15 & 14 & 1 & 34 \\
\hline Exercising in a group & 4.5 & 6 & 10 & 9 & 5 & 30 \\
\hline Water aerobics & 5.0 & 4 & 13 & 10 & 2 & 29 \\
\hline Home gymnastics & 4.0 & 7 & 4 & 6 & 4 & 21 \\
\hline Skiing & 7.0 & 4 & 10 & 6 & - & 20 \\
\hline Walking slowly & 2.0 & 2 & 5 & 8 & 4 & 19 \\
\hline Dancing & 4.0 & 3 & 7 & 8 & - & 18 \\
\hline Ballgames & 4.5 & 2 & 7 & 3 & 1 & 13 \\
\hline
\end{tabular}

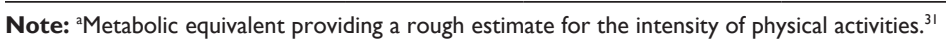

Abbreviations: COPD, chronic obstructive pulmonary disease; MET, metabolic equivalents; FEV , forced expiratory volume in I second.

daily life activity, mobility score, and HRQoL than with their level of bronchial obstruction. The subjective perception of dyspnea, captured by the MRC test, was significantly higher among inactive than active patients when $\mathrm{FEV}_{1}$ was less than $65 \%$ of expected levels. In the multivariate model, dyspnea remained the most significant explanatory factor for exercise inactivity. The findings are further supported by study designs in which dyspnea was better correlated with patients' performance during a 6-minute walking test than with a patient's $\mathrm{FEV}_{1}$ levels. ${ }^{36,37}$

Even though the proportion of inactive patients increased in parallel with disease progression, the participants showed great variation in activity as well as in sport choices. Sports that COPD patients favored were no different when compared to those favored by others in the population that were age- and sex-matched. ${ }^{38}$ The great majority of these patients exercised without any assistance from health care professionals, and only a minority of these patients had taken part in a pulmonary rehabilitation course or had received guidance about exercising. Across the whole cohort, $24 \%$ of the patients were extremely inactive during the wintertime, exercising only once or twice in the whole season, while the most active participants (10\%) exercised daily. Significant seasonal variations in exercise activity were found, and yearround exercise activity levels were better maintained among patients who exercised indoors (36\% of the study subjects). Based on demographics, comorbidities, or health behavior, active and inactive patients were very similar.

\section{Limitations and strengths of the study}

The study population was large and represented all severity levels of the disease. The gathered clinical variables were valid and comprehensive, but relied completely on retrospective health care data. The assessment of exercise activity was based on two questions, which were used in two previous Finnish Health Surveys in 2000 and 2011, allowing us to compare the results among COPD patients in subsequent studies with members of the Finnish population at large. ${ }^{25}$ These surveys also employed the more established International Physical Activity Questionnaire with extremely poor response rates. Based on that experience, we decided to use these two basic questions (Q1A and Q1B), which guaranteed us excellent response rates $(98 \%$ and $97 \%$, respectively), but the answers to these questions contained limited information. In particular, the intensity level of physical training was very roughly approximated.

Since our study relies completely on retrospective lung function data, the spirometry results presented here were not performed at the same time as the questionnaire survey, and this may have weakened the correlations observed in our results. The latest spirometry results were taken, on average, 1.7 years prior to recruitment. However, we had collected an average of 5.5 spirometry tests per patient during the follow-up period, ${ }^{24}$ and we performed simple sensibility testing using participants' baseline and bronchodilation spirometry results from different time points; we found that our basic findings did not change (data not shown). Thus, the time difference between the questionnaire survey and the physiological measures may not have played a major role in our results.

In addition to obstruction, restrictive impairment of $\mathrm{FVC}$ and thus the FEV/FVC ratio $>0.7$ is rather common in COPD. ${ }^{39,40}$ To avoid exclusion of a significant number of patients with combined lung function impairments from the analysis, we chose to classify the level of airway obstruction solely based on the $\mathrm{FEV}_{1}$ instead of the Global Initiative for 
Chronic Obstructive Lung Disease (GOLD) measurements. Unfortunately, diffusion capacity was available only for 285 patients, but the preliminary results showed an even smaller correlation between the sensation of dyspnea and exercise activity.

\section{Interpretation of findings in relation to previously published work}

Compared to an epidemiological study conducted in Sweden $(n=526)^{5}$ in which $84 \%$ of COPD patients were inactive, the Finnish COPD patients reported a higher level of physical activity. The difference can be at least partially explained by the 10-year age difference between the study populations. The patients in the present study have been participating actively for many years, and thus, to some degree, might represent a selected patient population. However, compared to the population from the Copenhagen Heart Study ( $n=6568)$, in which patients participated actively, the exercise activity levels noted in this study were more similar to the levels noted in our study. ${ }^{9}$ Approximately $19 \%$ of the Danish COPD patients showed low, 50\% moderate, and 32\% high physical activity levels.

\section{Interesting details in the activity profile}

Wintertime physical activity was evaluated separately from the rest of the year since COPD patients tend to become more symptomatic in cold and humid weather. ${ }^{41}$ The winter season before the study began was colder than average, as the temperature in southern Finland was below $0^{\circ} \mathrm{C}$ for 60 days. Our results confirmed that exercise activity decreased during the winter months when $\mathrm{FEV}_{1}$ was under $80 \%$ of expected levels. This might partially explain why year-round activity was better maintained among patients who also practiced indoor sports. A total of $17 \%$ of patients reported poor weather as a barrier to exercising; on the other hand, dog-walking was a rather popular leisure activity among $10 \%$ of the COPD patients from our study (Table S1), suggesting that motivation helps COPD patients tolerate cold weather. A history of competing in sports as a youth was reported in $35 \%$ of patients; contrary to findings noted among healthy individuals, no protection against physical inactivity was observed compared to their noncompeting counterparts at the time of the survey. ${ }^{42}$ It seems that COPD is a strong trigger for physical inactivity even among previous athletes. It is not known whether these former athletes would be more successful at restoring their physical capability and maintaining their exercise activity after pulmonary rehabilitation interventions than those who did not have a history of participating in sports as youth.

\section{Implications for future research, policy, and practice}

Dyspnea is the main symptom of COPD. This subjective experience of breathing discomfort is multidimensional, deriving from physiological, psychological, social, and environment factors, and is not directly comparable with physiological measurements. ${ }^{43,44}$ Limitations in exercise capacity among patients with COPD occur due to ventilatory limitation, dynamic hyperinflation, disturbances in respiratory muscles, ventilatory and vascular capacity imbalance, reduced oxygen uptake and hypoxemia, blood gases, and muscular metabolics. ${ }^{44,45}$ It is poorly understood why a significant proportion of patients who have very severe bronchial obstruction maintain remarkable levels of physical activity, while others start to lose their exercise capacity at early stages of disease. ., $^{29}$

Large variations in COPD patients' exercise capacity have also been described in studies in which patients' physical activity levels were measured with motion sensors. ${ }^{1-3}$ Dyspnea was strongly associated with exercise activity among the participants, even when adjusted for $\mathrm{FEV}_{1}$ and other clinically valid variables such as age, sex, comorbidities, smoking status, or BMI. This suggests that COPD either harms cardiovascular exercise capacity by mechanisms other than airway obstruction, or that dyspnea is secondary to physical inactivity and is a marker of overall impaired physical fitness. Pulmonary rehabilitation, combined with pre- and post-intervention physiological measurements for exercise capacity, will be of value in examining the causality between dyspnea and inactivity.

\section{Conclusion}

The present study suggests that patients' subjective sensations of dyspnea may be an indicator that patients' exercise routines should be assessed. On the other hand, the patients in the cohort currently studied reported dyspnea as the most common barrier to exercise. We should inform inactive patients that dyspnea is not a barrier for exercising and encourage them to exercise despite the sensation of dyspnea. Most of the current rehabilitation programs do not acknowledge patients' exercise history, nor do they aim to create more tailored programs, which would ultimately support the patient's own exercise preferences. These programs might achieve better long term results by introducing a variety of indoor and outdoor sports, which 
may help the patient find the most attractive ways for him or her to train and enjoy exercise.

\section{Acknowledgments}

The authors thank clinical research nurses Kerstin Ahlskog, Kirsi Sariola, and Päivi Laakso for their commitment to the study over the years and for skillfully organizing mailing campaigns. The authors also thank Tuula Lahtinen for monitoring the study, and they also thank Dr Ulla Hodgson for providing valuable advice. The COPEX study was supported by The Finnish Social Insurance Institution, and the original clinical follow-up study was supported by the Helsinki University Central Hospital (HUS EVO), University of Helsinki; the Foundation of the Finnish AntiTuberculosis Association; the Finnish Allergy Program by the Ministry of Health and Social Affairs; the Allergiasäätiö ry and Yrjö Jahnsson Foundation; and the Pulmonary Association Heli.

\section{Disclosure}

M Katajisto and the other authors did not have a financial relationship with any commercial entity that has an interest in the subject of this manuscript. M Katajisto has participated on the Advisory Board for Novartis and Leiras. She has received lecture fees from Boehringer-Ingelheim, Pfizer, Leiras, and Novartis, and a fee to act as a consultant for Boehringer. Helsinki University Central Hospital has sent her to medical congresses abroad, sponsored by many different pharmaceutical companies. T Laitinen is a member of the Boehringer-Ingelheim, Admirall, and Leiras Advisory Boards. She has received lecture fees, and Turku University Central Hospital has sent her to congresses abroad, sponsored by different pharmaceutical companies. M Kilpeläinen has been a member of the Pfizer advisory board. She has received lecture fees from Boehringer, Pfizer, GSK, and Novartis. Turku University Central Hospital has sent her to congresses abroad, sponsored by different pharmaceutical companies. Ari Lindqvist, Piritta Rantanen, Heikki Tikkanen, and Henna Kupiainen have no conflicts of interest.

\section{References}

1. Troosters T, Sciurba F, Battaglia S, et al. Physical inactivity in patients with COPD, a controlled multi-center pilot-study. Respir Med. 2010; 104(7):1005-1011.

2. Pitta F, Troosters T, Spruit MA, Probst VS, Decramer M, Gosselink R. Characteristics of physical activities in daily life in chronic obstructive pulmonary disease. Am J Respir Crit Care Med. 2005;171(9):972-977.

3. Watz H, Waschki B, Meyer T, Magnussen H. Physical activity in patients with COPD. Eur Respir J. 2009;33(2):262-272.
4. Bossenbroek L, de Greef MH, Wempe JB, Krijnen WP, Ten Hacken NH. Daily physical activity in patients with chronic obstructive pulmonary disease: a systematic review. COPD. 2011;8(4):306-319.

5. Arne M, Janson C, Janson S, et al. Physical activity and quality of life in subjects with chronic disease: chronic obstructive pulmonary disease compared with rheumatoid arthritis and diabetes mellitus. Scand J Prim Health Care. 2009;27(3):141-147.

6. Garcia-Aymerich J, Serra I, Gomez FP, et al; for Phenotype and Course of COPD Study Group. Physical activity and clinical and functional status in COPD. Chest. 2009;136(1):62-70.

7. Waschki B, Kirsten A, Holz O, et al. Physical activity is the strongest predictor of all-cause mortality in patients with COPD: a prospective cohort study. Chest. 2011;140(2):331-342.

8. Pitta F, Troosters T, Probst VS, Lucas S, Decramer M, Gosselink R. Potential consequences for stable chronic obstructive pulmonary disease patients who do not get the recommended minimum daily amount of physical activity. J Bras Pneumol. 2006;32(4):301-308.

9. Garcia-Aymerich J, Lange P, Benet M, Schnohr P, Anto JM. Regular physical activity reduces hospital admission and mortality in chronic obstructive pulmonary disease: a population based cohort study. Thorax. 2006;61(9):772-778.

10. Watz H, Waschki B, Boehme C, Claussen M, Meyer T, Magnussen H. Extrapulmonary effects of chronic obstructive pulmonary disease on physical activity: a cross-sectional study. Am J Respir Crit Care Med. 2008;177(7):743-751.

11. Agusti A, Calverley PM, Celli B, et al; Evaluation of COPD Longitudinally to Identify Predictive Surrogate Endpoints (ECLIPSE) investigators. Characterisation of COPD heterogeneity in the ECLIPSE cohort. Respir Res. 2010;11:122.

12. Rodriguez Gonzalez-Moro JM, de Lucas Ramos P, Izguierdo Alonso JL, et al. Impact of COPD severity on physical disability and daily living activities: EDIP-EPOC I and EDIP-EPOC II studies. Int $J$ Clin Pract. 2009;63(5):742-750.

13. Chapman KR, Mannino DM, Soriano JB, et al. Epidemiology and costs of chronic obstructive pulmonary disease. Eur Resp J. 2006;27(1): 188-207.

14. Buist AS, McBurnie MA, Vollmer WM, et al; for BOLD Collaborative Research Group. International variation in the prevalence of COPD (the BOLD Study): a population-based prevalence study. Lancet. 2007; 370(9589):741-750.

15. Anzueto A. Impact of exacerbations on COPD. Eur Respir Rev. 2010; 19(116):113-118.

16. Puhan M, Scharplatz M, Troosters T, Walters EH, Steurer J. Pulmonary rehabilitation following exacerbations of chronic obstructive pulmonary disease. Cochrane Database Syst Rev. 2009;1:CD005305. Review.

17. Man WD, Polkey MI, Donaldson N, Gray BJ, Moxham J. Community pulmonary rehabilitation after hospitalisation for acute exacerbations of chronic obstructive pulmonary disease: randomised controlled study. BMJ. 2004;329(7476):1209.

18. Rubí M, Renom F, Ramis F, et al. Effectiveness of pulmonary rehabilitation in reducing health resources use in chronic obstructive pulmonary disease. Arch Phys Med Rehabil. 2010;91(3):364-368.

19. Guell R, Casan P, Belda J, et al. Long-term effects of outpatient rehabilitation of COPD: a randomized trial. Chest. 2000;117(4):976-983.

20. Lacasse Y, Martin S, Lasserson TJ, Goldstein RS. Meta-analysis of respiratory rehabilitation in chronic obstructive pulmonary disease. A Cochrane systematic review. Eura Medicophys. 2007;43(4):475-485.

21. Casaburi R, ZuWallack R. Pulmonary rehabilitation for management of chronic obstructive pulmonary disease. N Engl J Med. 2009;360(13): 1329-1335.

22. Qaseem A, Wilt TJ, Weinberger SE; American College of Physicians; American College of Chest Physicians; American Thoracic Society; European Respiratory Society. Diagnosis and management of stable chronic obstructive pulmonary disease: a clinical practice guideline update from the American College of Physicians, American College of Chest Physicians, American Thoracic Society, and European Respiratory Society. Ann Intern Med. 2011;155(3):179-191. 
23. Nici L, Donner C, Wouters E; for ATS/ERS Pulmonary Rehabilitation Writing Committee. American Thoracic Society/European Respiratory Society statement on pulmonary rehabilitation. Am J Respir Crit Care Med. 2006;173(12):1390-1413.

24. Laitinen T, Hodgson U, Kupiainen H, et al. Real-world clinical data identifies gender-related profiles in chronic obstructive pulmonary disease. COPD. 2009;6(4):256-262.

25. Aromaa A, Koskinen S, editors. Health and Functional Capacity in Finland: Baseline Results of the Health 2000 Health Examination Survey. Helsinki: National Public Health Institute; 2004. Available from: http://www.terveys2000.fi/julkaisut/baseline.pdf. Accessed January 5, 2010.

26. Rasinaho M, Hirvensalo M, Leinonen R, Lintunen T, Rantanen T. Motives for and barriers to physical activity among older adults with mobility limitations. J Aging Phys Act. 2007;15(1):90-102.

27. Bestall JC, Paul EA, Garrod R, Garnham R, Jones PW, Wedzicha JA. Usefulness of the Medical Research Council (MRC) dyspnoea scale as a measure of disability in patients with chronic obstructive pulmonary disease. Thorax. 1999;54(7):581-586.

28. Haskell WL, Lee IM, Pate RR, et al. Physical activity and public health: updated recommendation for adults from the American College of Sports Medicine and the American Heart Association. Med Sci Sports Exer. 2007;39(8):1423-1434.

29. Barley EA, Quirk FH, Jones PW. Asthma health status measurement in clinical practice: validity of a new short and simple instrument. Respir Med. 1998;92(10):1207-1214.

30. Chen H, Eisner MD, Katz PP, Yelin EH, Blanc PD. Measuring diseasespecific quality of life in obstructive airway disease: validation of a modified version of the airways questionnaire 20. Chest. 2006;129(6): 1644-1652.

31. Hajiro T, Nishimura K, Jones PW, et al. A novel, short, and simple questionnaire to measure health-related quality of life in patients with chronic obstructive pulmonary disease. Am J Respir Crit Care Med. 1999;159(6):1874-1878.

32. Mazur W, Kupiainen H, Pitkäniemi J, et al. Comparison between the disease-specific Airways Questionnaire 20 and the generic 15D instruments in COPD. Health Qual Life Outcomes. 2011;9:4.

33. Sintonen H. The 15D instrument of health-related quality of life: properties and applications. Ann Med. 2001;33(5):328-336.

34. Viljanen AA, Halttunen PK, Kreus KE, Viljanen BC. Spirometric studies in non-smoking, healthy adults. Scand J Clin Lab Invest Suppl. 1982;159:5-20.
35. Ainsworth BE, Haskell WL, Whitt MC, et al. Compendium of physical activities: an update of activity codes and MET intensities. $\mathrm{Med} \mathrm{Sci}$ Sports Exerc. 2000;32(Suppl 9):S498-S504.

36. Spruit MA, Watkins ML, Edwards LD, et al; for Evaluation of COPD Longitudinally to Identify Predictive Surrogate Endpoints (ECLIPSE) study investigators. Determinants of poor 6-min walking distance in patients with COPD: the ECLIPSE cohort. Respir Med. 2010;104(6): 849-857.

37. Marin JM, Carrizo SJ, Gascon M, Sanchez A, Gallego B, Celli BR. Inspiratory capacity, dynamic hyperinflation, breathlessness, and exercise performance during the 6-minute-walk test in chronic obstructive pulmonary disease. Am J Respir Crit Care Med. 2001; 163(6):1395-1399.

38. Suomen Liikunta ja Urheilu [homepage on the Internet]. [National exercise report]. Helsinki, Finland: Suomen Liikunta ja Urheilu. Available from: http://www.slu.fi/liikuntatutkimus. Accessed 18 November, 2011. Finnish

39. Aaron SD, Dales RE, Cardinal P. How accurate is spirometry at predicting restrictive pulmonary impairment? Chest. 1999;115(3):869-873.

40. Wan ES, Hokanson JE, Murphy JR, et al; COPDGene Investigators. Clinical and radiographic predictors of GOLD-unclassified smokers in the COPDGene study. Am J Respir Crit Care Med. 2011;184(1): $57-63$.

41. Donaldson GC, Seemungal T, Jeffries DJ, Wedzicha JA. Effect of temperature on lung function and symptoms in chronic obstructive pulmonary disease. Eur Respir J. 1999;13(4):844-849.

42. Tammelin T, Nayha S, Laitinen J, Rintamaki H, Jarvelin MR. Physical activity and social status in adolescence as predictors of physical inactivity in adulthood. Prev Med. 2003;37(4):375-381.

43. Puhan MA, Garcia-Aymerich J, Frey M, et al. Expansion of the prognostic assessment of patients with chronic obstructive pulmonary disease: the updated BODE index and the ADO index. Lancet. 2009; 374(9691):704-711.

44. Nguyen HQ, Altinger J, Carrieri-Kohlman V, Gormley JM, Stulbarg MS. Factor analysis of laboratory and clinical measurements of dyspnea in patients with chronic obstructive pulmonary disease. J Pain Symptom Manage. 2003;25(2):118-127.

45. PepinV, Saey D, Laviolette L, Maltais F. Exercise capacity in chronic obstructive pulmonary disease: mechanisms of limitation. COPD. 2007; 4(3):195-204. 


\section{Supplementary material}

Table SI COPEX questionnaire and response rates among 719 COPD patients

\begin{tabular}{|c|c|c|c|c|}
\hline & \multicolumn{2}{|l|}{ COPEX questionnaire } & \multicolumn{2}{|c|}{$\begin{array}{l}\text { Response rate } \\
\text { n (\%) }\end{array}$} \\
\hline \multirow[t]{8}{*}{ QIA } & \multicolumn{2}{|c|}{$\begin{array}{l}\text { How often do you exercise at least half an hour at a time during the spring, summer, and autumn seasons } \\
\text { (at least mildly perspiring and being out of breath)? }\end{array}$} & & \\
\hline & \multicolumn{2}{|l|}{ I. Daily } & \multicolumn{2}{|l|}{$113(16.1 \%)$} \\
\hline & \multicolumn{2}{|l|}{ 2. 4-6 times a week } & \multicolumn{2}{|l|}{$117(16.6 \%)$} \\
\hline & \multicolumn{2}{|l|}{ 3. 2-3 times a week } & \multicolumn{2}{|l|}{202 (28.7\%) } \\
\hline & \multicolumn{2}{|l|}{ 4. Once a week } & \multicolumn{2}{|l|}{$85(12.1 \%)$} \\
\hline & \multicolumn{2}{|l|}{ 5. 2-3 times a month } & \multicolumn{2}{|l|}{$65(9.2 \%)$} \\
\hline & \multirow{2}{*}{\multicolumn{2}{|c|}{ 6. A few times or less }} & \multicolumn{2}{|l|}{$121(17.2 \%)$} \\
\hline & & & \multicolumn{2}{|l|}{ Total 703} \\
\hline \multirow[t]{8}{*}{ QIB } & \multicolumn{4}{|c|}{$\begin{array}{l}\text { How often do you exercise at least half an hour at a time during the winter season (at least mildly } \\
\text { perspiring and getting out of breath)? }\end{array}$} \\
\hline & I. Daily & & \multicolumn{2}{|l|}{71 (10.1\%) } \\
\hline & 2. 4-6 times a week & & \multicolumn{2}{|l|}{78 (11.1\%) } \\
\hline & 3. 2-3 times a week & & $202(28.8 \%)$ & \\
\hline & 4. Once a week & & $109(15.5 \%)$ & \\
\hline & 5. 2-3 times a month & & 71 (10.1\%) & \\
\hline & 6. A few times or less & & $170(24.3 \%)$ & \\
\hline & & & Total 701 & \\
\hline Q2 & How many minutes do you & daily on your way to work? & & \\
\hline & I. I do not work or I work & & $611(87.8 \%)$ & \\
\hline & 2. I go to work by motor $v$ & & $35(5.0 \%)$ & \\
\hline & 3. $<15$ minutes a day & & $12(1.7 \%)$ & \\
\hline & 4. $15-29$ minutes a day & & $17(2.4 \%)$ & \\
\hline & 5. $>30$ minutes a day & & $21(3.0 \%)$ & \\
\hline & & & Total 696 & \\
\hline Q3 & How physically strenuous is & & & \\
\hline & I. I do not work & & $614(87.3 \%)$ & \\
\hline & 2. I mostly sit & & $37(5.4 \%)$ & \\
\hline & 3. I walk a lot, but I do not & eavy items & $24(3.4 \%)$ & \\
\hline & 4. I walk a lot, lift and carr) & imb stairs or uphill & $23(3.3 \%)$ & \\
\hline & 5. My work is heavy physic & & $5(0.7 \%)$ & \\
\hline & & & Total 703 & \\
\hline Q4 & Domestic activities that yol & ek (mean $\pm S D)$ & Time (min) & Mean* \\
\hline & I. Vacuuming, cleaning & $\mathrm{h}_{\mathrm{h}} \mathrm{min} /$ week & $430(60 \%)$ & $85( \pm 66)$ \\
\hline & 2. Gardening, yard work & $\Gamma_{[} \mathrm{h} \_\mathrm{min} /$ week & 197 (27.5\%) & $206( \pm 192)$ \\
\hline & 3. Shopping & $\Gamma_{[} \mathrm{h} \_\mathrm{min} /$ week & 572 (80\%) & $157( \pm 116)$ \\
\hline & 4. Taking care of children & _ $\mathrm{h} \_\mathrm{min} /$ week & $42(5.9 \%)$ & $362( \pm 386)$ \\
\hline & 5. Taking the dog out & $\Gamma \mathrm{h}=\mathrm{min} /$ week & $72(10 \%)$ & $383( \pm 246)$ \\
\hline & 6. Something else & ${ }_{-} \mathrm{h} \_\mathrm{min} /$ week & 79 (11\%) & $313( \pm 300)$ \\
\hline & & & Total 716 & \\
\hline Q5 & Sports that you have practi & last year & & \\
\hline & Gym workout & & $62 / 9 \%$ & \\
\hline & Gymnastics & & $21 / 3 \%$ & \\
\hline & Dancing (anything) & & $18 / 3 \%$ & \\
\hline & Walking & & $235 / 33 \%$ & \\
\hline & Jogging & & $4 / 1 \%$ & \\
\hline & Cycling (in or out) & & $68 / 9 \%$ & \\
\hline & Swimming & & $48 / 7 \%$ & \\
\hline & Water aerobics & & $29 / 4 \%$ & \\
\hline & Water running & & $34 / 5 \%$ & \\
\hline & Yoga & & $7 / 1 \%$ & \\
\hline & Skiing & & $20 / 3 \%$ & \\
\hline & None & & $194 / 27 \%$ & \\
\hline
\end{tabular}


Table SI (Continued)

COPEX questionnaire

My exercising is restricted because (of):

I. Shortness of breath

2. Other illnesses (three most common)

3. Pain

4. I have been warned not to stress myself physically

5. Strenuous exercise feels uncomfortable

6. I do not feel safe outdoors

7. Why should I exercise?

8. I don't know where to exercise

9. I don't know how to exercise

10. I don't have time to exercise

II. I lack the company

12. Bad weather conditions

13. Exercising is too expensive

14. I have no possibilities to exercise in the neighborhood

15. Fear of injury

16. Another obstacle: what?
Response rate

n (\%)

$480(67 \%)$

$301(42 \%)$

$260(36 \%)$

$44(6.1 \%)$

$146(20 \%)$

$46(6.4 \%)$

10 (1.4\%)

$22(3.1 \%)$

$13(1.8 \%)$

$13(1.8 \%)$

$5 \mathrm{I}(7.1 \%)$

$121(17 \%)$

37 (5.2\%)

17 (2.4\%)

48 (6.7\%)

88 (I2\%)

$36(6 \%)$

$130(23 \%)$

397 (7I\%)

Total 563

$69(10.3 \%)$

$263(39 \%)$

202 (30\%)

96 (14.3\%)

4I (6.1\%)

Total 67I

7l (II\%)

$219(34 \%)$

62 (9.6\%)

$95(15 \%)$

198 (31\%)

Total 645

Yes 244 (35\%)

No 454 (65\%)

Total 698

445 (65\%)

97 (14\%)

$144(21 \%)$

57 (8.3\%)

39 (5.6\%)

Total 690

71 (10\%)

25 (3.8\%)

590 (85\%)

Total 69।

QI3 Have you got enough information about the role of physical activity in prognosis of your pulmonary disease?

I. Yes

$316(46 \%)$

2. No

377 (54\%)

Total 693

(Continued) 
Table SI (Continued)

\begin{tabular}{lll}
\hline COPEX questionnaire & $\begin{array}{l}\text { Response rate } \\
\text { n (\%) }\end{array}$ \\
\hline QI4 & Would you be interested in participating in pulmonary rehabilitation supporting, in particular, physical \\
activity and coordinated by a lung physician and physiotherapist? & $158(23.2 \%)$ \\
I. Yes, I-3 times a week in a small group for $2-3$ months & $229(34 \%)$ \\
2. Yes, I-2 weeks as an inpatient in a rehabilitation center & $192(28 \%)$ \\
3. I exercise as much as possible. I do not believe that I need pulmonary rehabilitation & $102(15 \%)$ \\
4. I am not interested in pulmonary rehabilitation & Total 68I \\
Have you been smoking during the last 6 months? & $212(29.9 \%)$ \\
I. Daily & $61(8.6 \%)$ \\
2. Every now and then & $436(61.5 \%)$ \\
3. Not at all & Total 709 \\
During the last 6 months, has your weight & $374(53 \%)$ \\
I. Stayed the same? & $195(28 \%)$ \\
2. Increased 2 kilograms or more? & $137(19 \%)$
\end{tabular}

Abbreviations: COPEX, COPd Exercise Study; COPD, chronic obstructive pulmonary disease.

Table S2 Correlation table between clinical variables and specific items in the questionnaire used in the COPEX study

\begin{tabular}{|c|c|c|c|c|c|c|c|c|c|}
\hline & & $\begin{array}{l}\text { Year-round } \\
\text { activity }\end{array}$ & $\begin{array}{l}\text { Domestic } \\
\text { activities } \\
\text { (Q4) }\end{array}$ & $\begin{array}{l}F E V_{1} \text { from } \\
\text { expected }\end{array}$ & $\begin{array}{l}\text { DLCOcVA } \\
\text { from } \\
\text { expected }\end{array}$ & $\begin{array}{l}\text { Subjective } \\
\text { dyspnea } \\
\text { MRC scale }\end{array}$ & $\begin{array}{l}\text { Mobility } \\
\text { score } \\
\text { (Q7) }\end{array}$ & $\begin{array}{l}\text { AQ20 } \\
\text { score }\end{array}$ & $\begin{array}{l}\text { I5D } \\
\text { score }\end{array}$ \\
\hline \multirow[t]{2}{*}{$\begin{array}{l}\text { Year-round } \\
\text { activity }\end{array}$} & $\begin{array}{l}\text { Correlation } \\
\text { coefficient }\end{array}$ & 1.000 & $-0.137^{* *}$ & $-0.174^{* *}$ & $-0.195 * *$ & $0.266 * *$ & $-0.314 * *$ & $0.188 * *$ & $-0.226 * *$ \\
\hline & $\mathrm{N}$ & 679 & 679 & 662 & 274 & 642 & 538 & 679 & 654 \\
\hline $\begin{array}{l}\text { Domestic } \\
\text { activities }\end{array}$ & $\begin{array}{l}\text { Correlation } \\
\text { coefficient }\end{array}$ & & 1.000 & $0.089^{*}$ & -0.033 & $-0.24 I^{* *}$ & $0.368^{* *}$ & $-0.088 *$ & $0.165^{* *}$ \\
\hline (Q4) & $N$ & & 697 & 679 & 283 & 656 & 550 & 697 & 671 \\
\hline \multirow[t]{2}{*}{ expected } & $\begin{array}{l}\text { Correlation } \\
\text { coefficient }\end{array}$ & & & 1.000 & $0.278 * *$ & $-0.358 * *$ & $0.172 * *$ & $-0.222^{* *}$ & $0.142^{* *}$ \\
\hline & $\mathrm{N}$ & & & 679 & 283 & 638 & 536 & 679 & 655 \\
\hline $\begin{array}{l}\text { DLCOcVA } \\
\text { from }\end{array}$ & $\begin{array}{l}\text { Correlation } \\
\text { coefficient }\end{array}$ & & & & 1.000 & $-0.254^{* *}$ & 0.088 & $-0.167 * *$ & 0.104 \\
\hline expected & $\mathrm{N}$ & & & & 283 & 263 & 224 & 283 & 279 \\
\hline $\begin{array}{l}\text { Subjective } \\
\text { dyspnea }\end{array}$ & $\begin{array}{l}\text { Correlation } \\
\text { coefficient }\end{array}$ & & & & & 1.000 & $-0.457 * *$ & $0.483 * *$ & $-0.452^{* *}$ \\
\hline MRC scale & $\mathrm{N}$ & & & & & 656 & 527 & 656 & 632 \\
\hline $\begin{array}{l}\text { Mobility score } \\
\text { (Q7) }\end{array}$ & $\begin{array}{l}\text { Correlation } \\
\text { coefficient }\end{array}$ & & & & & & 1.000 & $-0.326 * *$ & $0.403 * *$ \\
\hline (Q7) & $\mathrm{N}$ & & & & & & 550 & 550 & 528 \\
\hline \multirow[t]{2}{*}{ AQ20 score } & $\begin{array}{l}\text { Correlation } \\
\text { coefficient }\end{array}$ & & & & & & & 1.000 & $-0.705^{* *}$ \\
\hline & $\mathrm{N}$ & & & & & & & 697 & 671 \\
\hline \multirow[t]{2}{*}{ I5D score } & $\begin{array}{l}\text { Correlation } \\
\text { coefficient }\end{array}$ & & & & & & & & 1.000 \\
\hline & $\mathrm{N}$ & & & & & & & & 671 \\
\hline
\end{tabular}

Notes: $* P<0.05 ; * * P<0.01$.

Abbreviations: COPEX, COPd Exercise Study; DLCOcVA, diffusing capacity corrected for alveolar volume; MRC, British Medical Research Council; FEV , forced expiratory volume in I second.

International Journal of COPD

\section{Publish your work in this journal}

The International Journal of COPD is an international, peer-reviewed journal of therapeutics and pharmacology focusing on concise rapid reporting of clinical studies and reviews in COPD. Special focus is given to the pathophysiological processes underlying the disease, intervention programs, patient focused education, and self management protocols.
This journal is indexed on PubMed Central, MedLine and CAS. The manuscript management system is completely online and includes a very quick and fair peer-review system, which is all easy to use. Visit http://www.dovepress.com/testimonials.php to read real quotes from published authors. 